\title{
ANALISIS FAKTOR YANG MEMPENGARUHI KONSUMEN MEMBELI PRODUK MAKANAN PENDAMPING AIR SUSU IBU (MP-ASI) INSTAN
}

\author{
Nurselvi \\ Dosen Program Studi Teknik Industri, Fakultas Teknik, Universitas Pamulang \\ Dosen02045@unpam.ac.id
}

\begin{abstract}
ABSTRAK
Pada umumnyapada usia 6 bulan bayi memerlukan makanan pendamping air susu ibu (MPASI) karena pada fase ini bayi memerlukan banyak energi untuk berkembang dan nutrisinya tidak hanya bisa didapat hanya dari ASI saja. Penelitian ini bertujuan untuk menganalisis faktor apa saja yang mempengaruhi konsumen saat akan membeli MPASI instan. Faktor yang digunakan dalam penelitian ini adalah mutu yang melekat pada produk MPASI yaitu bentuk, tekstur, warna, aroma, rasa, kandungan nutrisi, bahan baku utama, bahan tambahan lain, kadaluarsa, harga, kemasan, hiegine produk dan keamanan produk.. Dari faktor tersebut didapat bahwa nutrisi, hiegine dan keamanan produk faktor yang mempengaruhi konsumen dalam membeli MPASI Instan.
\end{abstract}

Kata kunci : MPASI, ASI, Bayi

\section{PENDAHULUAN}

Pada umumnya saat usia 6 bulan bayi diberi makanan tambahan yang dikenal dengan makanan pendamping air susu ibu (MPASI). MP-ASI adalah makanan bergizi yang diberikan disamping ASI kepada bayi berusia 6 bulan keatas atau berdasarkan indikasi medik, sampai anak berusia 24 bulan untuk mencapai kecukupan gizi (SNI 01-7111, 2005). Ada dua bentuk MP-ASI instan yang beredar dipasaran yaitu bentuk bubuk instan dan biskuit. MPASI dalam bentuk bubuk instan banyak dipilih ibu untuk diberikan kepada anaknya karena mudah dalam menghidangkan dan kandungan nutrisi yang masih terjaga karena hanya sedikit mengalami tahapan pengolahan.

Berbagai merek MPASI dapat dengan mudah ditemui di pasar atau supermarket dengan berbagai macam keunggulan yang ditonjolkan oleh tiap produk MPASI. Fenomena di pasaran kadang beberapa varian produk memiliki rasa yang sama namun keunggulan yang berbeda. Misalnya samasama rasa beras merah namun, ada beberapa produk yang mengunggulkan dengan kalimat beras merah organik" dan lainnya.
Pada penelitian ini peneliti fokus kepada faktor apa saja yang mempengaruhi konsumen dalam memilih produk MPASI bubuk instan.

\section{DASAR TEORI}

Menurut Surat Keputusan Menteri Kesehatan Republik Indonesia nomor 224/Menkes/SK/II/2007 bahwa :

1. Rasa MP-ASI bubuk instan mempunyai tiga rasa yang disukai bayi yaitu: beras merah, kacang hijau dan pisang.

2. Kadaluarsa produk MP-ASI bubuk instan aman dikonsumsi dalam waktu 24 bulan setelah tanggal produksi.

3. Keamanan produk pangan juga harus diperhatikan dapat dilakukan dengan uji Total Plate Count (TPC), Coliforms, Escherichia coli, Salmonela dan Staphilococcus aureus.

\section{III.METODE DAN PENGUKURAN}

\section{A. Fokus Penelitian}

Agar memudahkan permasalahan yang dibahas maka Fokus penelitian ini dapat dilihat pada Gambar 1. 
Faktor yang mempengaruhi ibu dalam memilih MPASI Instan :

1. Bentuk

2. Tekstur

3. Warna

4. Aroma

5. Rasa

6. Kandungan nutrisi

7. Bahan baku utama

8. Bahan tambahan lain

9. Kadaluarsa

10. Harga

11.Kemasan

12.Hiegine

13.Keamanan

Gambar 1. Kerangka Pemikiran

\section{B. Etika Penelitian}

Etika penelitian adalah aturan yang harus ditaati peneliti sebelum memulai penelitian. peneliti meminta Surat izin penelitian ke dinas Perizinan dan Kesehatan kota Yogyakarta untuk melakukan penelitian di posyandu.

C. Populasi dan sampel

Populasi dalam penelitian ini adalah populasi terjangkau oleh peneliti yaitu jumlah kelahiran hidup kota Yogyakarta tahun 2013 sebesar 44.839 jiwa (Profil kesehatan kota Yogyakarta, 2013).

Penelitian ini menggunakan teknik pengambilan sampel non probability dengan Purpossive sampling yang artinya teknik pengambilan sampel yang tidak memberi peluang/kesempatan yang sama bagi setiap unsur atau anggota populasi untuk dipilih menjadi sampel dimana pengambilan sampel dilakukan dengan pertimbangan tertentu. Sampel yang digunakan adalah ibu yang bayinya mengikuti kegiatan posyandu dibawah pengawasan Puskesmas Gondokusuman II. Pemilihan lokasi sampel dengan pertimbangan dari Puskesmas Gondokusuman II. Penentuan jumlah sampel dapat menggunakan persamaan Slovin.

$$
n=\frac{N}{1+N(e)^{2}}
$$

Dimana :

$\mathrm{n}$ : ukuran sampel

$\mathrm{N}$ : ukuran populasi e : persen kelonggaran ketidaktelitian karena kesalahan pengambilan sampel yang masih ditolerir (sampling error)

Dalam menghitung jumlah sampel digunakan error $10 \%$. Berdasarkan rumus Slovin tersebut, ukuran sampel yang harus diambil adalah :

$$
\begin{aligned}
& n=\frac{44.839}{1+44.839(0,1)^{2}} \\
& n=\frac{44.839}{448,4}=99,99 \approx 100 \text { responden }
\end{aligned}
$$

Berdasarkan perhitungan diatas maka jumlah sampel yang diambil untuk dijadikan responden adalah 100 responden.

\section{IV.HASIL DAN PEMBAHASAN}

\section{A. Deskripsi Responden}

Dari responden sebanyak 100 orang yang ditemui di posyandu wilayah GondokusumanII didapat profil responden yang dijelaskan sebagai berikut :

Tabel 1. Karakteristik Usia Ibu

\begin{tabular}{llc}
\hline Usia & Jumlah & Prosentase \\
\hline 20-25 tahun & 20 & $20 \%$ \\
26-31 tahun & 45 & $45 \%$ \\
$32-37$ tahun & 25 & $25 \%$ \\
$38-43$ tahun & 10 & $10 \%$ \\
\hline Total & $\mathbf{1 0 0}$ & $\mathbf{1 0 0 \%}$ \\
\hline Sumber : Data olahan primer, 2016
\end{tabular}


Dari tabel 1 diketahui bahwa konsumen MPASI Bubuk instan paling banyak adalah ibu yang berumur 26-31 tahun sebanyak 30\%, kemudian diikuti 32-37 tahun sebanyak 25\% dan 20-25 tahun sebanyak $20 \%$.

Tabel 2. Karakteristik Pekerjaan Ibu

\begin{tabular}{llc}
\hline Pekerjaan & Jumlah & Prosentase \\
\hline $\begin{array}{l}\text { Ibu rumah } \\
\text { tangga }\end{array}$ & 68 & $68 \%$ \\
$\begin{array}{l}\text { Karyawan } \\
\text { swasta }\end{array}$ & 16 & $16 \%$ \\
$\begin{array}{l}\text { Wiraswasta } \\
\text { Pegawai negri }\end{array}$ & 4 & $4 \%$ \\
sipil & 12 & $12 \%$ \\
\hline Total & $\mathbf{1 0 0}$ & $\mathbf{1 0 0 \%}$ \\
\hline
\end{tabular}

Sumber : Data olahan primer, 2016

Dari tabel 2 diketahui bahwa konsumen

MPASI bubuk instan sebanyak $68 \%$ ibu rumah tangga, 16\% Karyawan swasta dan 12\% Pegaai Negri Sipil.

Tabel 3. Karakteristik Usia Bayi

\begin{tabular}{llc}
\hline Usia & Jumlah & Prosentase \\
\hline 6-12 bulan & 40 & $40 \%$ \\
13-18 bulan & 16 & $16 \%$ \\
19-24 bulan & 44 & $44 \%$ \\
$6-12$ bulan & 40 & $40 \%$ \\
\hline Total & $\mathbf{1 0 0}$ & $\mathbf{1 0 0 \%}$
\end{tabular}

Sumber : Data olahan primer, 2016

Karakteristik usia bayi ini maksudnya usia bayi yang datang mengunjungi posyandu dan semua bayi pernah mengkonsumsi MPASI Bubuk instan.

Tabel 4. Karakteristik Jenis Kelamin Bayi

\begin{tabular}{lll}
\hline Jenis Kelamin & Jumlah & Prosentase \\
\hline Perempuan & 61 & $61 \%$ \\
Laki-laki & 49 & $49 \%$ \\
\hline Total & 100 & $100 \%$ \\
\hline \multicolumn{3}{l}{ Sumber : Data olahan primer, 2016 }
\end{tabular}

Dari tabel 4 diketahui bahwa sebanyak $61 \%$ bayi perempuan dan $49 \%$ bayi laki-laki yang datang ke posyandu.

\section{B. Hasil Penelitian}

Identifikasi atribut mutu produk, dilakukan dengan studi literatur yang mengacu pada standar SNI MP-ASI bubuk instan nomor 01-7111-2005 (2005) dan diskusi dengan petugas kesehatan ibu anak dan ahli nutrisi makanan mengenai faktor-faktor apa saja yang harus diperhatikan pada produk MPASI.atribut produk yang digunakan adalah atribut produk yang melekat pada produk itu sendiri.Dari diskusi dengan petugas kesehatan ibu dan anak, ahli nutrisi makanan serta wawancara yang dilakukan kepada ibu yang memiliki bayi yang mengonsumsi MP-ASI bahwa :

1. Warna perlu diperhatikan karena warna merupakan salah satu faktor penarik konsumen untuk mengonsumsi makanan.

2. Aroma juga mempengaruhi tingkat penerimaan konsumen tarhadap produk makanan.

3. Harga merupakan salah satu faktor yang mempengaruhi konsumen dalam memberi produk.

Dari pertimbangan diatas maka peneliti merumuskan atribut mutu yang dianggap penting diperhatikan dalam MP-ASI bubuk instan yaitu bentuk, tekstur, warna, aroma, rasa, kandungan nutrisi, bahan baku utama, bahan tambahan lain, kadaluarsa, harga, kemasan, hiegine produk dan keamanan produk. Untuk memberikan persamaan persepsi responden maka atribut mutu tersebut harus didefinisikan lebih spesifik.Atribut mutu MP-ASI bubuk instan dapat dilihat pada tabel 5 .

Tabel 5. Atribut mutu MP-ASI bubuk instan

\begin{tabular}{ll}
\hline Atribut mutu & Definisi \\
\hline Bentuk* & Bentuk MP-ASI bubuk instan \\
Tekstur* & $\begin{array}{l}\text { Tekstur MP-ASI bubuk instan pada saat } \\
\text { diencerkan dengan air hangat }\end{array}$ \\
Warna*** & $\begin{array}{l}\text { Warna tampilan MP-ASI bubuk instan pada saat } \\
\text { diencerkan dengan air hangat }\end{array}$ \\
Aroma*** & $\begin{array}{l}\text { Aroma MP-ASI bubuk instan pada saat } \\
\text { diencerkan dengan air hangat }\end{array}$ \\
Rasa** & Rasa MP-ASI bubuk instan saat disajikan \\
Kandungan nutrisi* & Kandungan nutrisi yang terkandung dalam MP-
\end{tabular}


Bahan baku utama*

Bahan tambahan lain*

Kadaluarsa**

Harga $* * *$

Kemasan*

Higine produk*

Keamanan produk**
ASI bubuk instan

Varian bahan baku MP-ASI bubuk instan

Perisa yang ditambahkan untuk menguatkan

rasa MP-ASI bubuk instan

Waktu kadaluarsa setelah produksi

Harga MP-ASI bubuk instan yang sesuai dengan kualitas dan dapat diterima oleh konsumen

Ukuran kemasan MP-ASI bubuk instan

Bahan kemasan MP-ASI bubuk instan

Cara proses produksi MP-ASI bubuk instan

Cemaran mikroorganisme yang mungkin

mencemari MP-ASI bubuk instan

Sumber :

*SNI MP-ASI bubuk instan nomor 01-7111-2005

**Surat Keputusan Menteri Kesehatan Republik Indonesia nomor 224/Menkes/SK/II/2007

***Hasil diskusi dengan ahli gizi dan petugas kesehatan

Kuesioner yang berisi tentang atribut mutu produk kemudian diuji validitas dan reliabilitas. Uji validitas menggunakan SPSS 20 metode Pearson Product moment yang merupakan teknik korelasi dalam statistik parametris digunakan untuk mencari hubungan dan membuktikan hipotesis hubungan dua variabel bila data kedua variabel berbentuk interval atau rasio dan sumber data dari dua variabel atau lebih tersebut adalah sama (Sugiono, 2008). Hasil validitas dan reliabilitas dapat dilihat pada tabel 6 .

Tabel 6. Hasil validitas dan reliabilitas

\begin{tabular}{|c|c|c|c|c|}
\hline \multirow[b]{2}{*}{ Atribut mutu } & \multicolumn{2}{|c|}{ Validitas } & \multicolumn{2}{|c|}{ Reliabilitas } \\
\hline & $\begin{array}{c}\text { Koefisien } \\
\text { korelasi }\end{array}$ & Ket & $\begin{array}{c}\text { Koefisien } \\
\text { alpha }\end{array}$ & Ket \\
\hline Bentuk & 0,43 & Valid & 0,81 & Reliabel \\
\hline Tekstur & 0,59 & Valid & 0,79 & Reliabel \\
\hline Warna & 0,42 & Valid & 0,82 & Reliabel \\
\hline Aroma & 0,47 & Valid & 0,80 & Reliabel \\
\hline Rasa & 0,61 & Valid & 0,79 & Reliabel \\
\hline Nutrisi & 0,54 & Valid & 0,80 & Reliabel \\
\hline Bahan baku & 0,69 & Valid & 0,78 & Reliabel \\
\hline Bahan tambahan lain & $\theta, 19$ & Tidak Valid & & \\
\hline Kadaluarsa & 0,59 & Valid & 0,79 & Reliabel \\
\hline Harga & 0,69 & Valid & 0,79 & Reliabel \\
\hline Ukuran kemasan & 0,39 & Valid & 0,82 & Reliabel \\
\hline Bahan kemasan & 0,51 & Valid & 0,81 & Reliabel \\
\hline Hiegine produk & 0,62 & Valid & 0,79 & Reliabel \\
\hline Keamanan produk & 0,62 & Valid & 0,79 & Reliabel \\
\hline
\end{tabular}

Sumber : Data olahan Primer, 2016

Berdasarkan hasil perangkingan atribut mutu produk dari keinginan konsumen maka dipilih atribut mutu yaitu nutrisi, higine produk, keamanan produk, bahan baku dan rasa sebagai atribut mutu yang selanjutnya dijadikan acuan untuk membuat kuesioner identifikasi keinginan konsumen.

Penentuan tingkat kepentingan atribut mutu bertujuan untuk menentukan prioritas pengembangan produk MP-ASI bubuk instan. Hasil data yang diperoleh kemudian dihitung bobot dari masing-masing atribut tersebut. Atribut dengan bobot tertinggi akan memiliki nilai tingkat kepentingan yang tinggi bagi responden dan akan memiliki rangking yang tinggi sehingga perlu diprioritaskan dalam perancangan konsep. Prioritas pengembangan atribut mutu produk dapat dlihat pada tabel 7 .

Tabel 7.Perankingan Faktor yang mempengaruhi konsumen

\begin{tabular}{lclc}
\hline Atribut & Tingkat kepentingan & Bobot & Rangking prioritas \\
\hline Nutrisi & 3,61 & 0,09 & 1
\end{tabular}




\begin{tabular}{llll} 
Higine produk & $\mathbf{3 , 3 2}$ & $\mathbf{0 , 0 8}$ & $\mathbf{2}$ \\
Keamanan produk & $\mathbf{3 , 3 1}$ & $\mathbf{0 , 0 8}$ & $\mathbf{3}$ \\
Bahan baku & $\mathbf{3 , 2 7}$ & $\mathbf{0 , 0 8}$ & $\mathbf{4}$ \\
Rasa & $\mathbf{3 , 2 1}$ & $\mathbf{0 , 0 8}$ & $\mathbf{5}$ \\
Kadaluarsa & 3,20 & 0,08 & 6 \\
Tekstur & 3,17 & 0,08 & 7 \\
Bahan kemasan & 3,04 & 0,07 & 8 \\
Bentuk & 2,90 & 0,07 & 9 \\
Ukuran kemasan & 2,81 & 0,07 & 10 \\
Aroma & 2,75 & 0,06 & 11 \\
Warna & 2,52 & 0,06 & 12 \\
Harga & 2,51 & 0,06 & 13 \\
\hline
\end{tabular}

Sumber : Data olahan Primer, 2016

Berdasarkan hasil perangkingan atribut mutu produk dari keinginan konsumen maka dipilih atribut mutu ranking 1-5 yaitu nutrisi, higine produk, keamanan produk, bahan baku

\section{KESIMPULAN}

Berdasarkan penelitian ini didapat bahwa nutrisi, hiegine dan keamanan produk faktor yang mempengaruhi konsumen dalam membeli MPASI Instan.

\section{DAFTAR PUSTAKA}

Fikawati, S. Syafiq, A. Karima, K. (2015). Gizi Ibu dan Bayi. Rajawali Pers, Jakarta.

SK-Menkes RI No.224. (2007). Spesifikasi Teknis Makanan Pendamping Air Susu Ibu (MP-ASI). Menteri Kesehatan Republik Indonesia, Jakarta.

SNI 01-7111-2005. (2005). MP-ASI Bagian 1 : Bubuk Instan. Dewan Standarisasi Nasional, Jakarta.

Sugiono. (2008). Statistik Untuk Penelitian. Bandung : Alfabeta

Ulrich,K.T. dan Eppinger S.D. (2001). Perancangan dan Pengembangan Produk (penerjemah Nora Azmi dan Iveline Anne Marie). Jakarta : Salemba Teknika.

World Health Organization. 2009. Infant and young Children Feeding. WHO, France. dan rasa sebagai atribut mutu yang selanjutnya dijadikan acuan untuk membuat kuesioner lanjutan (kuesioner identifikasi keinginan konsumen)

Budi, T. S., Supriyadi, E., \& Zulziar, M. (2018). ANALISIS KONFIGURASI PROSES PRODUKSI COKELAT STICK COVERTURE MENGGUNAKAN METODE DESIGN OF EXPERIMENTS (DOE) DI PT. GANDUM MAS KENCANA. JITMI (Jurnal IImiah Teknik dan Manajemen Industri), 1(1), 87-96.

Kurnia, D., Bastuti, S., \& Istiqomah, B. N. (2018). ANALISIS PENGENDALIAN BAHAN BAKU PADA PRODUK TAS DENGAN MENGGUNAKAN METODE MATERIAL REQUIREMENTS PLANNING (MRP) UNTUK MEMINIMALKAN BIAYA PENYIMPANAN DI HOME INDUSTRY AMEL COLLECTION. JITMI (Jurnal Ilmiah Teknik dan Manajemen Industri), 1(1), 22-28.

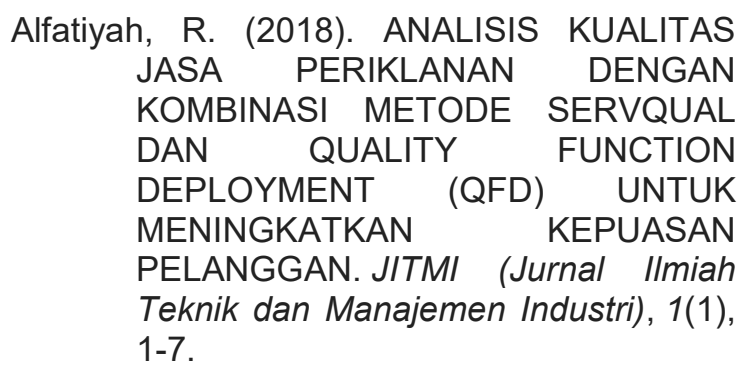

